\title{
Fuzzy and predictive control of a photovoltaic pumping system based on three-level boost converter
}

\author{
Zakaria Massaq, Abdelouahed Abounada, Mohamed Ramzi \\ LACEM, Faculty of Sciences and Technology, Beni-Mellal, Morocco
}

\begin{tabular}{l}
\hline \hline Article Info \\
\hline Article history: \\
Received May 6, 2020 \\
Revised Dec 5, 2020 \\
Accepted Apr 7, 2021 \\
\hline
\end{tabular}

\section{Keywords:}

Fuzzy logic control

Model predictive control

Photovoltaic

Variable step-size MPPT

Water pumping system

\begin{abstract}
In this work, an efficient control scheme for a double stage pumping system is proposed. On the DC side, a three-level boost converter is employed to maximize the photovoltaic power and to step-up the DC-link voltage. For maximum power point tracking, the classical incremental conductance method is substituted by a fuzzy logic controller. The designed controller estimates the optimal step size which speeds up the tracking process and improves the accuracy of the extracted photovoltaic power. Afterwards, the voltages across the three-level boost converter (TLBC) capacitors are balanced by phase shifting the applied duty ratios. On the motor pump side, a two-level inverter drives the motor pump with the cascaded nonlinear predictive control. The predictive controller is preferred over the conventional field-oriented control because it accelerates the torque response and resists to the change of the engine parameters. The designed controllers are evaluated using MATLAB/Simulink, and compared with the conventional controllers (incremental conductance algorithm and field-oriented control). The robust control scheme of the entire system has increased the hydraulic power by up to $23 \%$ during the system start-up and up to $10 \%$ in steady state.
\end{abstract}

This is an open access article under the CC BY-SA license.

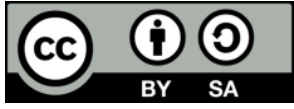

\section{Corresponding Author:}

Zakaria Massaq

Department of Electrical Engineering

Faculty of Sciences and Technology

B.P: 523 Beni-Mellal, Morroco

Email: zakaria.massaq@gmail.com

\section{INTRODUCTION}

The in the last decades, solar photovoltaic (PV) energy becomes the best alternative for water pumping systems because it produces clean energy [1], they are available in the rural or isolated areas [2] and the maintenance cost is reduced two to four times less than the diesel pumping systems [3]. Incremental conductance (IC) and hill climbing (HC) and are the most employed techniques for MPPT, due to their less complexity and good tracking accuracy [4]. However, those algorithms with fixed step size suffer from slow convergence speed, significant steady-state error and high oscillation amplitude [5]. Therefore, other faster and more efficient MPPT techniques were introduced in the literature such as fuzzy logic-MPPT (FL-MPPT) [6], artificial neural network based-maximum power point tracking (ANN-MPPT) [7] and others were proposed in the literature [8].

The three-level boost converter (TLBC) offers useful features for high power applications comparing to the two-level boost converter such as reducing switching losses, reduced inductor size [9], [10], the voltage stress applied to the power devices is less and the output capacitors are smaller [11]. Nevertheless, the capacitor voltages should be balanced. Various techniques were introduced in the literature 
to resolve this problem. In [12], [13] a phase delay and a PI controller are used for the voltage balance. Paper [14] introduced a model predictive control to achieve the voltage balance through the minimization of the cost function.

Solar pumping systems based on induction motors (IM) are widespread in the agriculture sector because the IM is simple, more efficient, low cost and robust [15]. From the control point view, the control of the speed and flux is very complicated because the asynchronous motor model is non-linear and the flux is not always measurable [16]. One of the most common techniques to drive the asynchronous motor is fieldoriented control (FOC), which is discovered by Blaschke [17], [18]. However, the FOC method is highly influenced by internal parameters variation of the engine and external load disturbances [19]. To get rid of FOC problems many non-linear control methods have been introduced such as input-output linearization (IOL), sliding mode control (SMC), and non-linear predictive control (NPC) [20]. The NPC has received particular attention due to its capacity to eliminate the weaknesses of the FOC [21]. The NPC task is to track the reference trajectories of flux and speed. This achieved through the calculation of the optimal control vector which minimizes the predicted tracking errors [22].

This work suggests an effective control scheme for a PV pumping system based on a TLBC, where an improved IC algorithm based on a FLC is developed to mitigate the drawbacks of the conventional IC. In order to benefit from the advantages of the TLBC a phase shift technique is implemented for the voltage balance. On the other hand, another FLC is suggested for DC-link voltage regulation to guarantee a correct operation of the DC-AC converter. The cascaded NPC is applied to control the IM because it resists to internal and external disturbances effectively. Finally, a series of simulations are done to confirm the effectiveness of the developed controllers. In the conclusion part, the main contribution of this article is explained, followed by a general conclusion with some perspectives for future works.

\section{CIRCUIT CONFIGURATION}

The boost converter in pumping systems plays two important roles [23], ensuring the maximum power tracking under normal or shading conditions [24], and increasing the voltage in the DC-bus to meet the recommended voltage. In this work, the boost converter is replaced with the three-level boost converter to benefit from the salient features of the TLBC in pumping systems. The studied topology presented in Figure 1 consists of a photovoltaic source, a TLBC responsible for tracking the maximum power, a voltage source inverter that controls an asynchronous motor (AM) and a centrifugal pump.

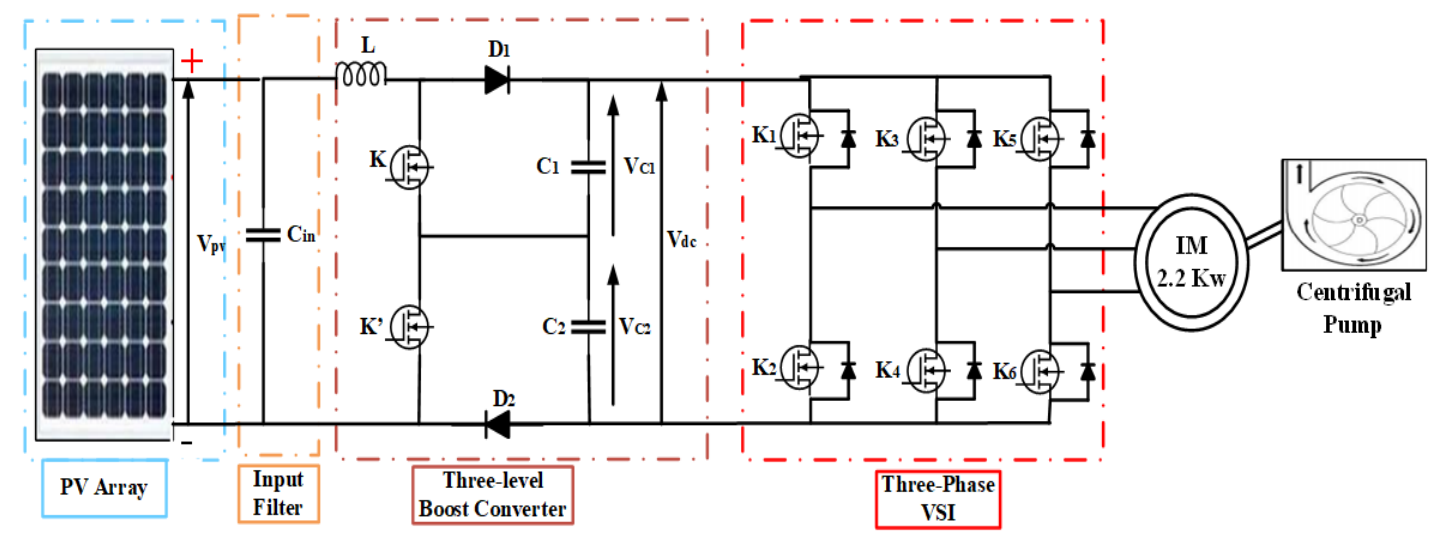

Figure 1. PV water pumping system based on TLBC

\section{CONTROL STRATEGY}

The developed control strategies for the water pumping system are: Control of the TLBC for MPPT and for the voltages balance and controlling the three-phase inverter to drive the induction motor under different environmental conditions.

\subsection{Control of the three-level boost converter}

The control scheme of the TLBC aims to: Extraction of the maximum power from the PV array with a variable step size IC algorithm. Balancing the voltages VC1 and VC2 with the phase shift method. 


\subsubsection{Fuzzy logic and incremental inductance algorithm}

The traditional IC method is inspired from perturb and observe algorithm, where the slope of PowerVoltage characteristic is null $\left(\mathrm{dP}_{\mathrm{pv}} / \mathrm{dV}_{\mathrm{pv}}=0\right)$ at the MPP [4], which is equivalent to $\left(\mathrm{dI}_{\mathrm{pv}} / \mathrm{dV}_{\mathrm{pv}}+\mathrm{I}_{\mathrm{pv}} / \mathrm{V}_{\mathrm{pv}}=0\right)$. In other words, the IC algorithm consists of comparing the dynamic conductance $\mathrm{dI}_{\mathrm{pv}} / \mathrm{dV}_{\mathrm{pv}}$ with the ratio $\mathrm{I}_{\mathrm{pv}} / \mathrm{V}_{\mathrm{pv}}$. The flowchart of the IC technique is represented in Figure 2.

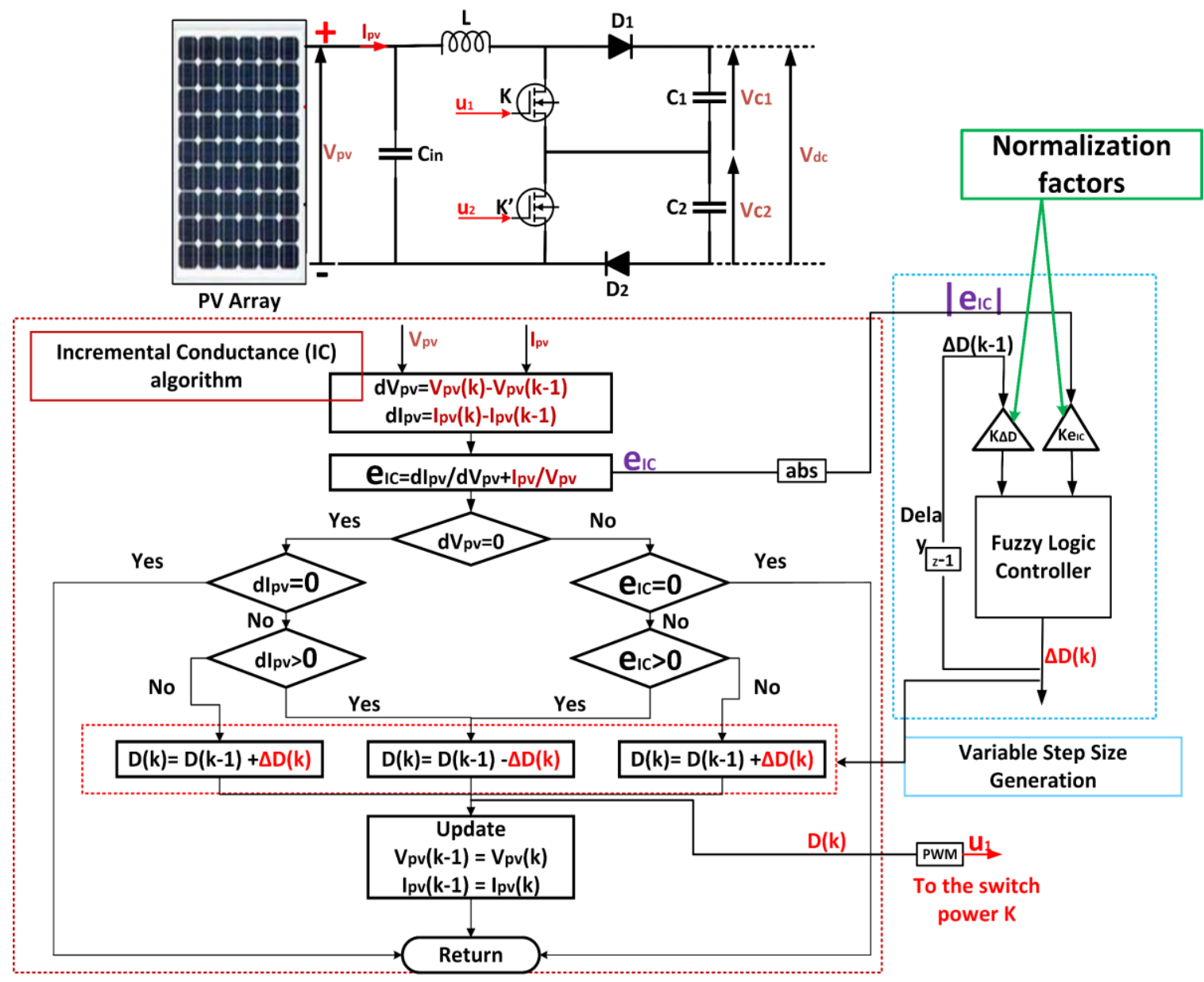

Figure 2. The enhanced IC technique for the MPPT

The classical IC technique works typically with constant step size, but the non-judicious choice of the step size might decrease the efficiency of the PV system. The choice of a big step size accelerates the power tracking under fast changes of the weather, while the power fluctuations increase in steady-state. Conversely, a small chosen step size reduces the amplitude of power oscillations when the insolation is almost fixed, but the IC algorithm converges slowly to the optimal MPP. In order to overcome the drawbacks relative to the classical IC, an FLC based on the incremental conductance principle is developed to generate a variable incremental duty ratio $\Delta \mathrm{D}(\mathrm{k})$, in which the step-size $\Delta \mathrm{D}(\mathrm{k})$ varies proportionally to the absolute error $\left|\mathrm{e}_{\mathrm{IC}}\right|$ (given in (1)) and the previous value of the incremented duty cycle $\Delta \mathrm{D}(\mathrm{k}-1)$, respectively. Afterward, the generated step size is sent to the conventional IC algorithm to search the MPP, as depicted in Figure 2. The optimal step size is computed with the Takagi-Sugeno type FLC. The absolute error $\left|e_{I C}\right|$ and the previous incremented duty ratio $\Delta \mathrm{D}(\mathrm{k}-1)$ are the two inputs of the fuzzy estimator, respectively. The fuzzy estimator is constituted with 25 rules presented in Table 1. Moreover, the membership functions Figure 3 of the inputs and the output are described with the following labels: $\mathrm{P}++, \mathrm{P}+, \mathrm{P}, \mathrm{P}-, \mathrm{P}--$. Where $\mathrm{P}$ indicates a positive input or output, and $+/$ - signs indicate the degree of positivity.

$$
\left|e_{I C}(k)\right|=\left|d I_{p v}(k) / d V_{p v}(k)+I_{p v}(k) / V_{p v}(k)\right|
$$




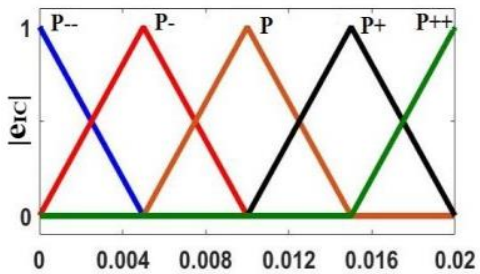

(a)

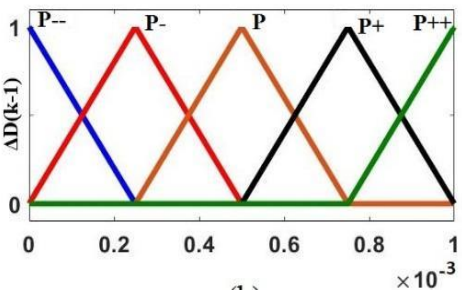

(b)

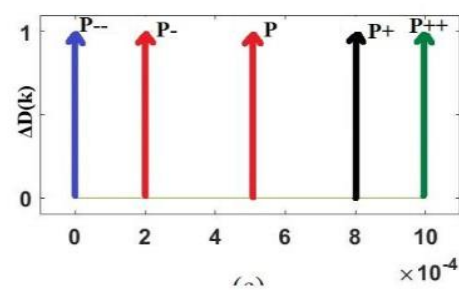

(c)

Figure 3. The membership functions, (a) The absolute error (|eIc|), (b) The previous step size $(\Delta \mathrm{D}(\mathrm{k}-1))$,

(c) The incremented duty cycle $(\Delta \mathrm{D}(\mathrm{k}))$

Table 1. FLC rules

\begin{tabular}{|c|c|c|c|c|c|}
\hline$\Delta \mathrm{D}(\mathrm{k}-1)$ & P-- & P- & $\mathrm{P}$ & $\mathrm{P}+$ & $\mathrm{P}++$ \\
\hline P-- & P-- & P- & $\mathrm{P}$ & $\mathrm{P}+$ & $\mathrm{P}++$ \\
\hline P- & P-- & P- & $\mathrm{P}$ & $\mathrm{P}+$ & $\mathrm{P}++$ \\
\hline$P$ & P-- & P- & $\mathrm{P}$ & $\mathrm{P}+$ & $\mathrm{P}++$ \\
\hline $\mathrm{P}+$ & P-- & P- & P- & $\mathrm{P}$ & $\mathrm{P}+$ \\
\hline $\mathrm{P}++$ & P-- & P- & P- & $\mathrm{P}$ & $\mathrm{P}+$ \\
\hline
\end{tabular}

\subsubsection{Output voltage balance with the phase-shift technique}

The voltage balance of the TLBC capacitors is necessary because it allows the devices with a lower voltage rating to operate in high voltage [11]. The phase-shift technique is employed to drive the switch $\mathrm{K}^{\prime}$ with a constant frequency [12]. In perfect conditions, the control signals of the switches $\mathrm{K}$ and $\mathrm{K}^{\prime}$ are phase-shifted with $180^{\circ}$. However, the voltage balance of the outputs $\mathrm{V}_{\mathrm{C} 1}$ and $\mathrm{V}_{\mathrm{C} 2}$ is not always ensured. Therefore, the PWM signal $\mathrm{u}_{1}$ is shifted forward or backward according to the algorithm shown in Figure 4 until the balance is adequately achieved [25].

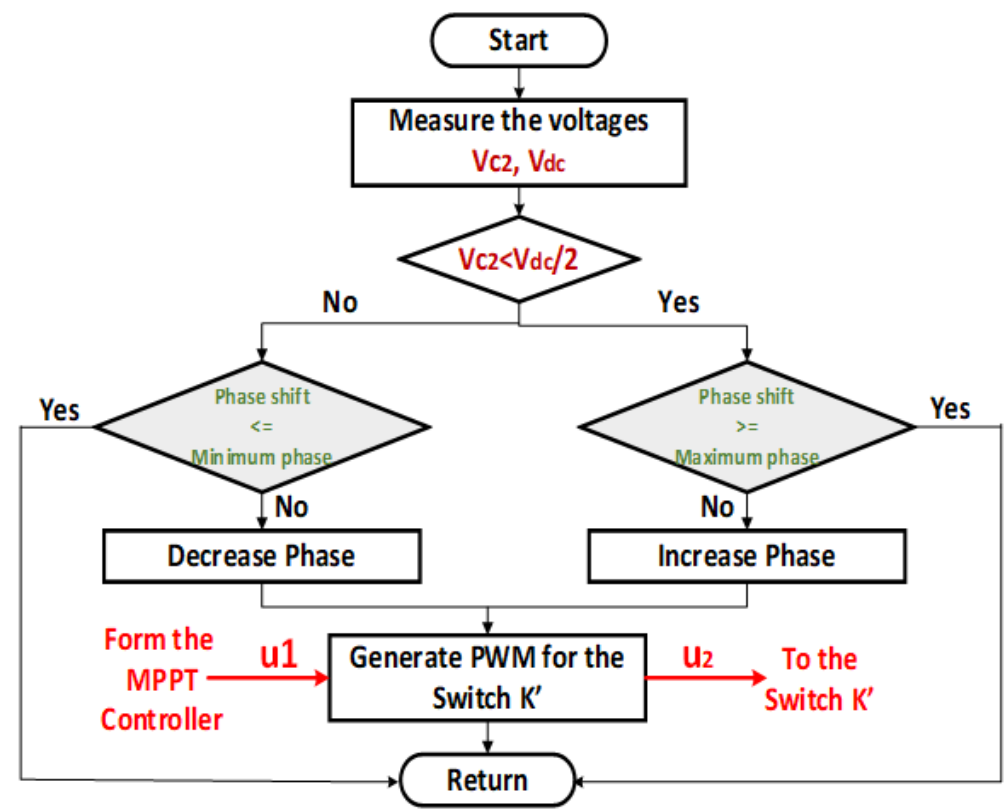

Figure 4. Flowchart of the phase-shift technique for the voltage balance

\subsection{The control strategy the three-phase inverter}

The control scheme of the inverter presented in Figure 5 aims to: Regulation the voltage $\mathrm{V}_{\mathrm{dc}}$ with an intelligent FLC for a correct commutation of the inverter. Controlling the speed $\omega_{\mathrm{m}}$ of the asynchronous motor with a cascaded non-linear predictive controller (CNPC). 


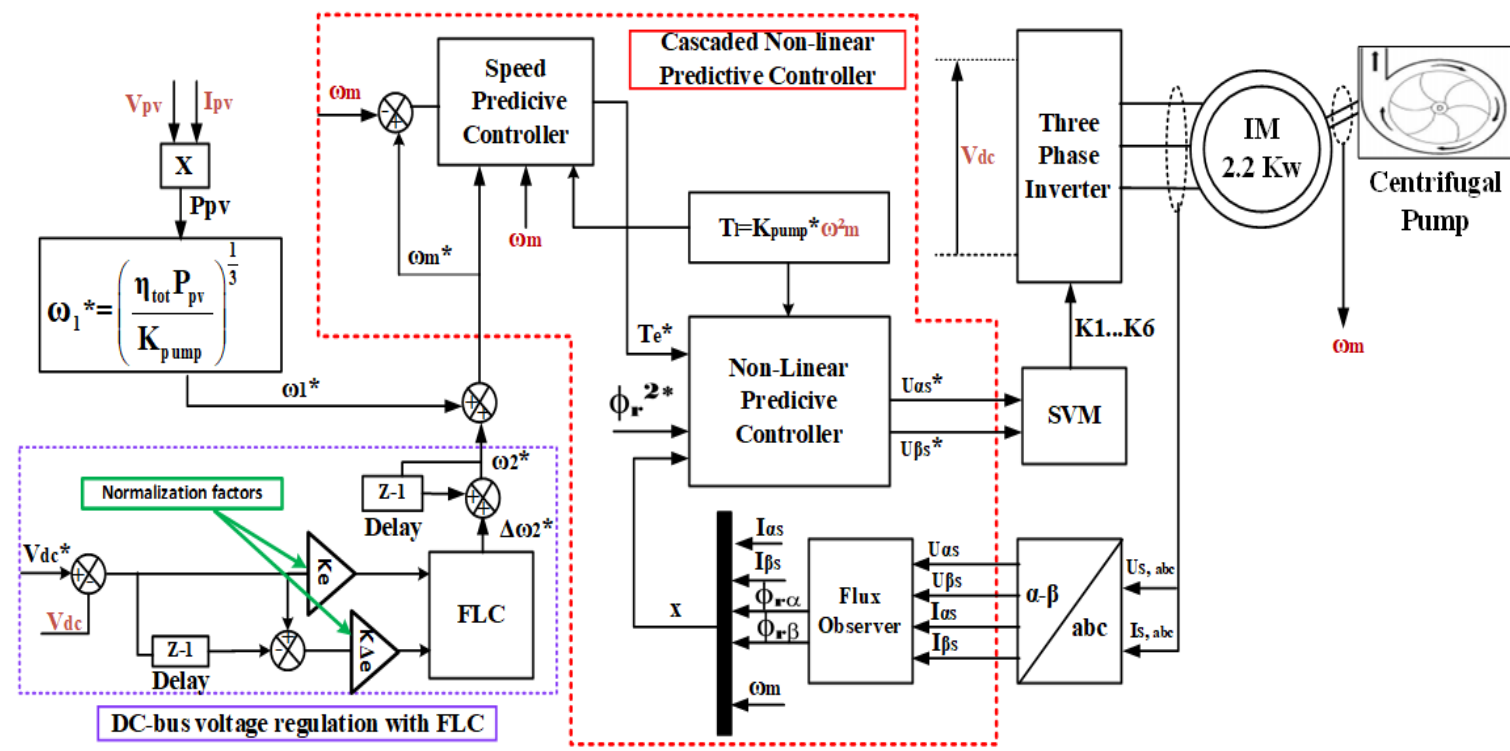

Figure 5. The proposed control strategies for the two-level inverter

\subsubsection{DC-link voltage regulation with an FLC}

The main idea behind the control of the autonomous pumping system is to transform the instantaneous extracted power $\mathrm{P}_{\mathrm{pv}}$ into a mechanical power $\mathrm{P}_{\mathrm{m}}$. By respecting the efficiency of the static converters $\eta_{\text {tot }}$, the estimated maximum speed is calculated as [23], [26],

$$
\omega_{1}^{*}=\left(\eta_{t o t} P_{p v} / K_{p u m p}\right)^{1}
$$

Where, $\mathrm{K}_{\text {pump }}$ is the pump constant. The load torque is calculated with the following expression [26], [27].

$$
T_{l}=K_{\text {pump }} \omega_{m}^{2}
$$

The DC-bus voltage could be regulated by adjusting the speed $\omega_{1}{ }^{*}$. When the voltage $\mathrm{V}_{\mathrm{dc}}$ exceeds its reference, the speed should be increased and vice versa [28]. In this work, a Mamdani type FLC is designed to adjust this speed, as depicted in Figure 5. The voltage error $\left(\mathrm{e}_{\mathrm{dc}}=\mathrm{V}_{\mathrm{dc}}{ }^{*}-\mathrm{V}_{\mathrm{dc}}(\mathrm{k})\right)$ and its change of error $\Delta \mathrm{e}_{\mathrm{dc}}$ $\left(\Delta \mathrm{e}_{\mathrm{dc}}=\mathrm{e}_{\mathrm{dc}}{ }^{*}-\mathrm{e}_{\mathrm{dc}}(\mathrm{k})\right)$ are the two inputs of the FLC, and the incremented speed $\Delta \omega_{2}$ is the output. The designed FLC is constituted with 25 rules presented in Table 2. Moreover, the membership functions Figure 6 of the inputs and the output variables are described with the following labels: $\mathrm{P}++, \mathrm{P}+, \mathrm{O}, \mathrm{N}-$ and $\mathrm{N}--. \mathrm{P}(\mathrm{N})$ indicates a positive (negative) input/output, and $\mathrm{O}$ indicates a zero input/output.

Table 2. FLC rules

\begin{tabular}{cccccc}
\multicolumn{5}{c}{ Table 2. FLC rules } \\
$\mathrm{e}_{\mathrm{dc}}(\mathrm{k})$ & $\mathrm{N}-\mathrm{e}_{\mathrm{dc}}$ & $\mathrm{N}-$ & $\mathrm{O}$ & $\mathrm{P}+$ & $\mathrm{P}++$ \\
\hline $\mathrm{N}--$ & $\mathrm{P}++$ & $\mathrm{P}+$ & $\mathrm{P}++$ & $\mathrm{P}++$ & $\mathrm{O}$ \\
$\mathrm{N}-$ & $\mathrm{P}+$ & $\mathrm{P}+$ & $\mathrm{P}+$ & $\mathrm{O}$ & $\mathrm{P}+$ \\
$\mathrm{O}$ & $\mathrm{N}-$ & $\mathrm{N}-$ & $\mathrm{O}$ & $\mathrm{P}+$ & $\mathrm{P}+$ \\
$\mathrm{P}+$ & $\mathrm{N}-$ & $\mathrm{O}$ & $\mathrm{N}-$ & $\mathrm{N}-$ & $\mathrm{N}-$ \\
$\mathrm{P}++$ & $\mathrm{O}$ & $\mathrm{N}-$ & $\mathrm{N}-$ & $\mathrm{N}--$ & $\mathrm{N}-$ \\
\hline
\end{tabular}

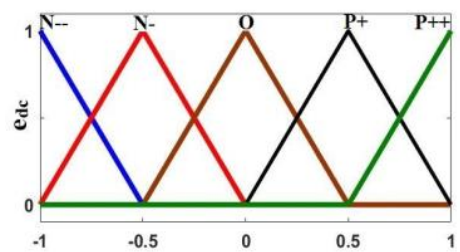

(a)

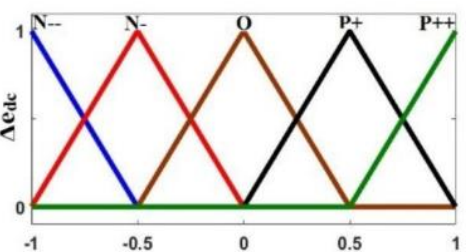

(b)

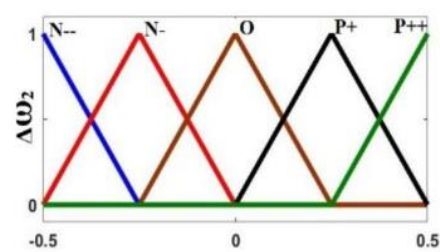

(c)

Figure 6. Membership functions, (a) Error $\mathrm{e}_{\mathrm{dc}}$, (b) $\Delta \mathrm{e}_{\mathrm{dc}}$, (c) $\Delta \omega_{2}$

Fuzzy and predictive control of a photovoltaic pumping system based on... (Zakaria Massaq) 


\subsubsection{Cascaded non-linear predictive control}

The objective of the CNPC is to realize a synchronized control of the three variables (speed, flux, and torque) with two loops. Each loop is designed with a generalized predictive controller [21], as shown in Figure 5. First, an external loop controls the speed; then, the inner loop controls other variables [16], [21].

a. Design of the internal loop controller

The continuous model of the IM in the fixed reference frame $(\alpha, \beta)$ is given by [17].

$$
\dot{x}=f(x)+g(x) \mathrm{u}(\mathrm{t})
$$

Where, $\quad \mathrm{x}=\left[\mathrm{i}_{\mathrm{s} \alpha} \mathrm{i}_{\mathrm{s} \beta} \phi_{1 \alpha} \phi_{r \beta} \omega_{m}\right]^{\mathrm{T}}, \quad u(t)=\left[u_{s \alpha} \mathrm{u}_{s \beta}\right]^{T}$

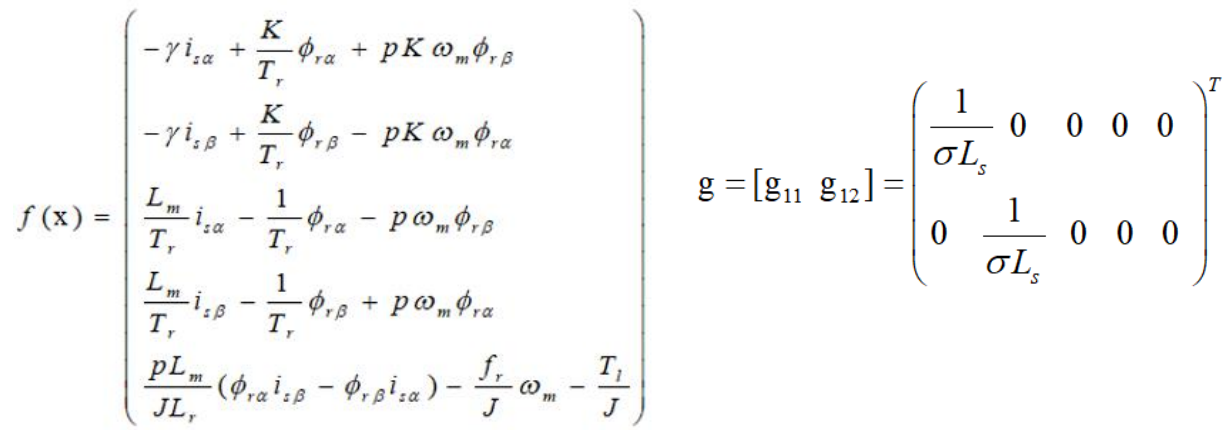

Where, $\mathrm{u}_{\mathrm{s} \alpha}, \mathrm{u}_{\mathrm{s} \beta}$ are stator voltages, $\mathrm{i}_{\mathrm{s} \alpha}, \mathrm{i}_{\mathrm{s} \beta}$ are stator currents, and $\phi_{\mathrm{r} \alpha}, \phi_{\mathrm{r} \beta}$ are rotor fluxes. Others constants are defined as,

$$
\sigma=1-\left(\frac{\mathrm{L}_{\mathrm{m}}{ }^{2}}{\mathrm{~L}_{\mathrm{s}} \mathrm{L}_{\mathrm{r}}}\right) ; K=\frac{L_{m}}{\sigma L_{s} L_{r}} ; \gamma=\frac{1}{\sigma L_{s}}\left(R_{s}+R_{r} \frac{L_{m}{ }^{2}}{L_{r}{ }^{2}}\right)
$$

Where, $\mathrm{T}_{1}$ load torque, $\mathrm{L}_{\mathrm{s}}, \mathrm{L}_{\mathrm{r}}, \mathrm{L}_{\mathrm{m}}$ are stator, rotor, and mutual inductances, $\mathrm{p}$ number of poles pair, $\mathrm{J}$ inertia coefficient, $f_{r}$ friction coefficient, $R_{s}, R_{r}$ are stator and rotor resistances, and $T_{r}=L_{r} / R_{r}$ rotor time constant. In the inner loop, the rotor flux and the torque are the variables to be regulated.

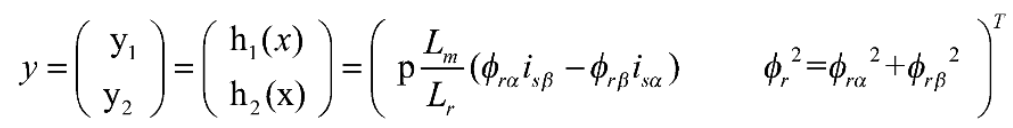

The Lie derivatives calculation of the outputs $\left(\mathrm{y}_{1}, \mathrm{y}_{2}\right)$ is given by:

$$
Y(t)=\left[\begin{array}{lll}
\mathrm{y}(\mathrm{t}) & \dot{y}(\mathrm{t}) & \ddot{y}(\mathrm{t})
\end{array}\right]^{T}=Y_{1}(t)+G_{1}(x) u(t)
$$

Where,

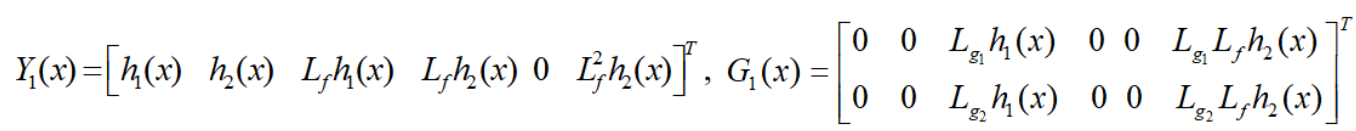

The main idea behind the non-linear predictive control is to calculate the optimal vector $u(t)$ which minimizes the cost function in (7). The quadratic cost function $\mathrm{J}$ to be minimized is defined in a finite time of prediction $\left(\mathrm{t}+\tau_{\mathrm{r}}\right)$ by,

$$
J=\frac{1}{2} \int_{0}^{\tau_{r}}\left(y(t+\tau)-\mathrm{y}_{r}(\mathrm{t}+\tau)\right)^{T}\left(\mathrm{y}(\mathrm{t}+\tau)-\mathrm{y}_{r}(\mathrm{t}+\tau)\right) \mathrm{d} \tau
$$

Employing Taylor series expansion for the output vector $y(t)$ and for the reference output vector $\mathrm{y}_{\mathrm{r}}(\mathrm{t})$. The cost function in (7) can be simplified as [17], [21], 


$$
J=\left(\mathrm{Y}_{1}(t)+G_{1}(x) u(t)-Y_{r}(\mathrm{t})\right)^{T} \bar{\Pi}\left(\mathrm{Y}_{1}(t)+G_{1}(x) u(t)-Y_{r}(\mathrm{t})\right)
$$

Where, $\quad Y_{r}(t)=\left(\mathrm{y}_{r_{1}}(\mathrm{t}) \mathrm{y}_{r_{2}}(\mathrm{t}) \quad \dot{y}_{r_{1}}(\mathrm{t}) \dot{y}_{r_{2}}(\mathrm{t}) \quad 0 \quad \ddot{y}_{r_{2}}(\mathrm{t})\right)^{T} \quad, \quad y_{r}=\left(T_{e}^{*} \phi_{r}^{2 *}\right)^{T} \quad$ and $\quad \bar{\Pi}=\int_{0}^{\tau_{r}} \overline{\mathrm{T}}(\tau)^{T} \overline{\mathrm{T}}(\tau) d \tau$

The optimal control vector $\mathrm{u}(\mathrm{t})$ is given by [21],

$$
\partial J / \partial u=0 \quad \Leftrightarrow \quad u(t)=\left[G_{1}^{T}(x) \bar{\Pi} G_{1}(x)\right]^{-1} G_{1}^{T}(x) \bar{\Pi}\left[Y_{r}(t)-Y(t)\right]
$$

b. Design of the external loop controller

The external loop is a simple predictive controller that controls the speed $\omega_{\mathrm{m}}$ by generating the optimal torque $\mathrm{T}_{\mathrm{e}}{ }^{*}$. The optimal control law is deduced from the cancellation of the tracking error defined by [21],

$$
\dot{\omega}\left(t+\tau_{r}\right)-\omega^{*}\left(t+\tau_{r}\right)=0
$$

Where, $\dot{\omega}\left(t+\tau_{r}\right)=\omega(t)+\tau_{r}\left(-\frac{f_{r}}{J} \omega(t)+\frac{1}{J} T_{e m}(t)-\frac{1}{J} T_{l}(t)\right) \quad$ and $\quad \omega^{*}\left(t+\tau_{r}\right)=\omega^{*}(t)+\tau_{r} \dot{\omega}^{*}(t)$

The optimal electromagnetic torque is deduced from (10).

$$
T_{e m}^{*}(t)=-\frac{J}{\tau_{r}}\left(\omega(t)-\omega^{*}(t)\right)+f_{r} \omega(t)+J \dot{\omega}^{*}(t)+\mathrm{T}_{1}(\mathrm{t})
$$

\section{SIMULATION RESULTS AND ANALYSIS}

In order to assess the performance of the developed controllers, some simulations are carried out with a dynamic insolation profile, as shown in Figure 7(a). The irradiance profile is varied over a wide range to evaluate the robustness of the proposed controllers. At the beginning, the insolation changes linearly from $800 \mathrm{~W} / \mathrm{m}^{2}$ to $400 \mathrm{~W} / \mathrm{m}^{2}$, thereafter, it is increased from $400 \mathrm{~W} / \mathrm{m}^{2}$ to $1000 \mathrm{~W} / \mathrm{m}^{2}$. The developed control scheme is compared with the conventional one (fixed step size IC algorithm for MPPT, and field-oriented control to drive the asynchronous motor). The basic parameters of the studied system are given in Table 3.

At first, the PV power controlled with the modified IC algorithm is compared to the PV power controlled with the conventional IC. To reconcile between the tracking speed and the rate of power oscillations a medium fixed step size $\Delta \mathrm{D}=5 \times 10^{-4}$ is chosen. Figure 7(b) exhibits the improvement of the extracted power with the modified version of the IC algorithm in terms of convergence speed toward the MPP and the reduction of oscillation amplitude around this point, as well as, the adaptive IC provides high accuracy of power tracking during steady state. With the proposed MPPT, the tracking speed becomes faster especially at the starting, the starting setting time for the modified IC is about $0.35 \mathrm{~s}$ and $0.7 \mathrm{~s}$ for the conventional IC. Table 4 summarizes the main PV power data in terms of the average steady-state power (Avg. Pow.) and the amplitude of oscillations around the MPP (Pow. Osc.). For the classical IC, the accuracy of power tracking is deteriorated at the lowest irradiances, in on the other hand, for the modified IC the accuracy in steady-state is increased by $10.8 \%$ and $6.38 \%$ under $400 \mathrm{~W} / \mathrm{m}^{2}$ and $450 \mathrm{~W} / \mathrm{m}^{2}$, respectively.

On the other side, analyzing the DC-bus voltage curve, it can be noticed that the voltage $\mathrm{V}_{\mathrm{dc}}$ stills

\begin{tabular}{|c|c|c|}
\hline & Parameter & Value \\
\hline PV Generator & $\begin{array}{c}\text { Optimal power at STC }\left(25^{\circ} \mathrm{C}\right. \\
\left.\text { and } 1000 \mathrm{~W} / \mathrm{m}^{2}\right)\end{array}$ & $2.4 \mathrm{Kw}$ \\
\hline \multirow{4}{*}{$\begin{array}{l}\text { Asynchronous } \\
\text { Motor }\end{array}$} & Nominal power & $2.2 \mathrm{Kw}$ \\
\hline & Nominal speed & $150 \mathrm{rad} / \mathrm{s}$ \\
\hline & Line to line voltage & $230 \mathrm{~V}$ \\
\hline & Nominal rotor flux & $0.6 \mathrm{~Wb}$ \\
\hline
\end{tabular}
close to its reference, as depicted in Figure 7(c). Furthermore, Figure 7(d) demonstrates that the capacitor voltages are always balanced even in a rapid change of insolation level. From the same figure, it is found that the instantaneous absolute error between the two voltages is always less than $0.4 \mathrm{~V}\left(\left|\mathrm{~V}_{\mathrm{C}_{1}}-\mathrm{V}_{\mathrm{C} 2}\right|<0.4 \mathrm{~V}\right)$.

Fuzzy and predictive control of a photovoltaic pumping system based on... (Zakaria Massaq) 
Table 4. Comparison study between the two MPPT techniques

\begin{tabular}{ccccccc}
\hline & 800 & 400 & 450 & 700 & 650 & 1000 \\
\hline & Avg. Pow. & Avg. Pow. & Avg. Pow. & Avg. Pow. & Avg. Pow. & Avg. Pow. \\
& Pow. Osc. & Pow. Osc. & Pow. Osc. & Pow. Osc. & $\begin{array}{c}\text { Pow. Osc. } \\
\text { (W) (W) }\end{array}$ & Pow. Osc. \\
& (W) $(W)$ & (W) $(W)$ & (W) $(W)$ & (W) $(W)$ & & \\
Conventional & 1934.20 .2 & 967.50 .1 & 1089.850 .1 & 1695.50 .1 & 1575.40 .2 & 2404.40 .4 \\
Proposed & 1932.10 .7 & 8633 & 10204 & 1694.50 .5 & 15752.2 & 2402.22 \\
\hline
\end{tabular}

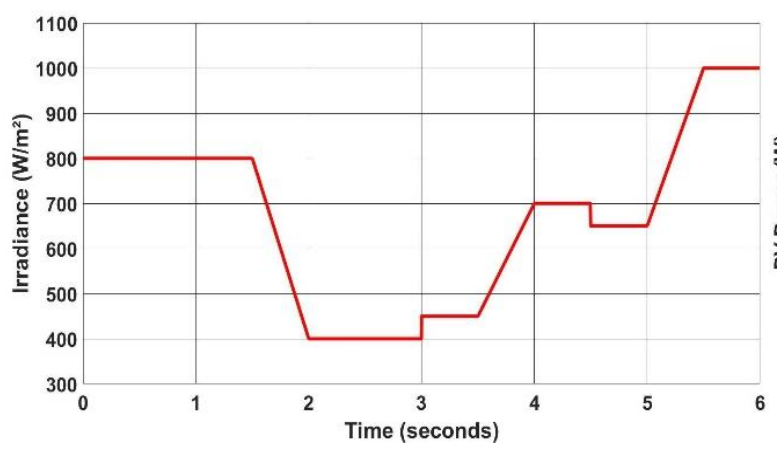

(a)

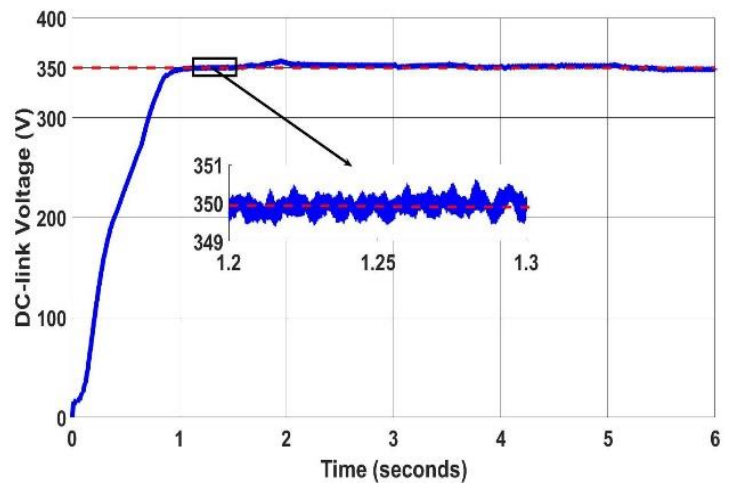

(c)

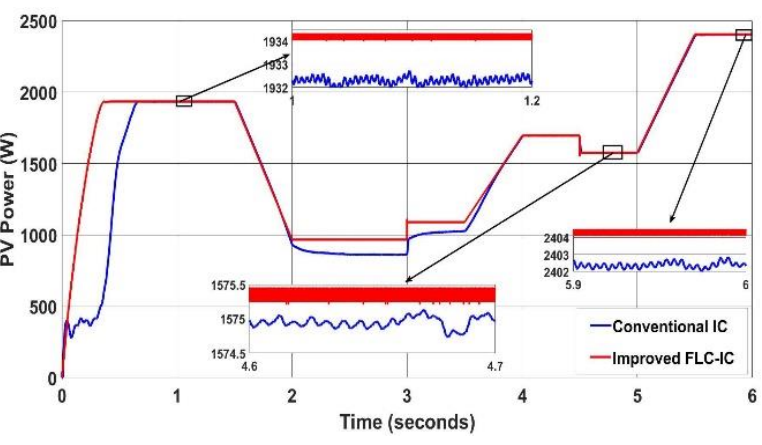

(b)

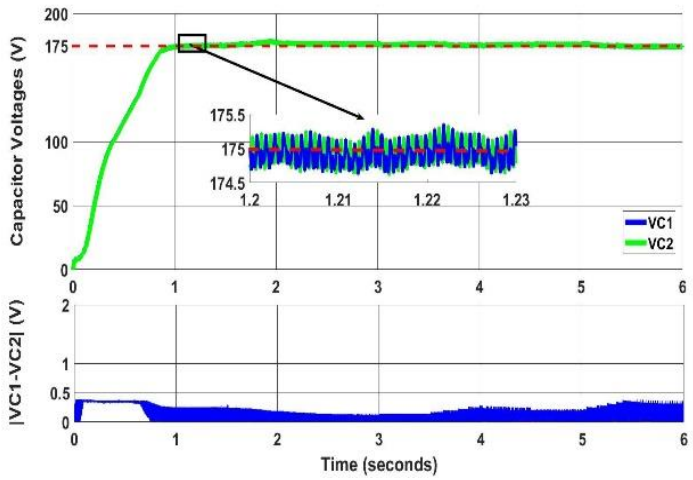

(d)

Figure 7. Simulation results, (a) Irradiance, (b) PV power, (c) DC-link voltage, (d) Voltages of capacitors

It can be seen from the speed waveforms in Figure 8(a) that the CNPC lets the AM follows the trajectory of the reference speed with an excellent dynamic. In contrast, the speed controller based on FOC takes more time to reach the desired speed. The internal CNPC loop generates the optimal control law which minimizes the torque error; for this reason, the NPC controller provides the best transient torque response and the torque ripples are minimized by $50 \%$ for some irradiations, as shown in Figure 8(b). On the other hand, Figure 8(c) demonstrates that the inner loop controller lets the rotor flux stuck to its reference; this ensures an ideal decoupling between the flux and the torque. Conversely, it can be observed from the same figure that the FOC presents a partial decoupling between the torque and the flux in transient conditions because the module of the rotor flux is slightly affected.

Since the modified IC tracks the MPP accurately and the IM performs with high performances with the proposed controllers, then the output hydraulic power is improved. A comparison summary in terms of the hydraulic power is presented in Figure 8(d). It can be observed from this figure that the hydraulic power is increased by $23.3 \%$ for the non-conventional control scheme during the starting period, the significant improvement of the hydraulic power during this period is due to the short setting time of the PV power to reach the optimal power and the fast response of the AC machine. For the remainder of the intervals, the lower PV power fluctuation and the better dynamic in steady state of the IM make the proposed control scheme the best in terms of power improvement, by having an improvement range of $2 \%$ to $10 \%$ in steady state. 


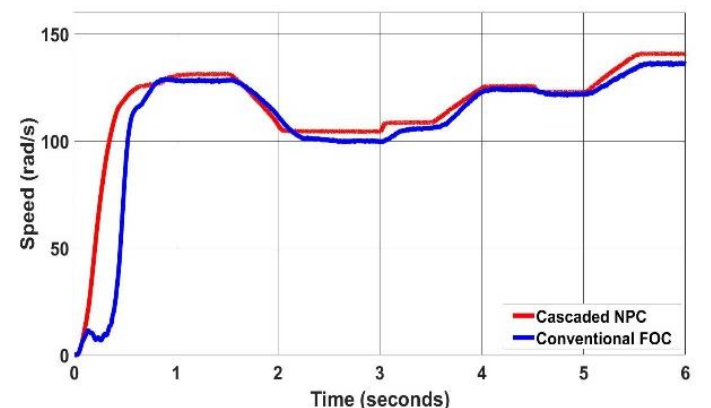

(a)

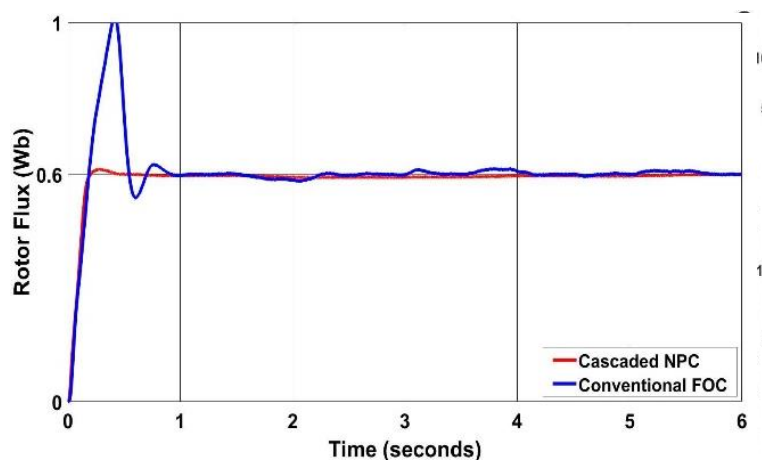

(c)

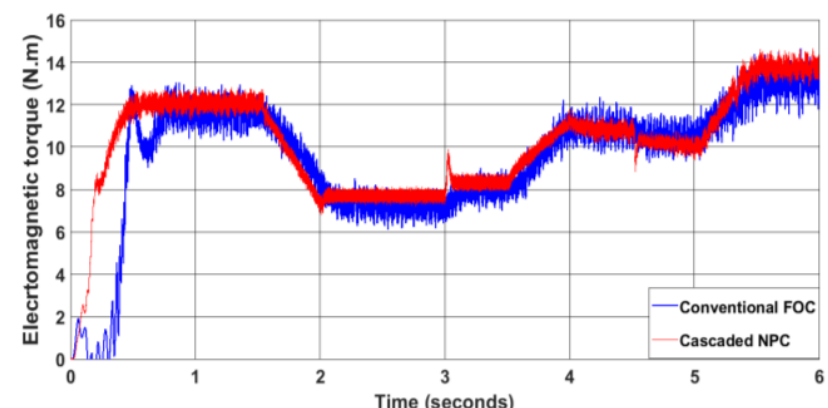

(b)

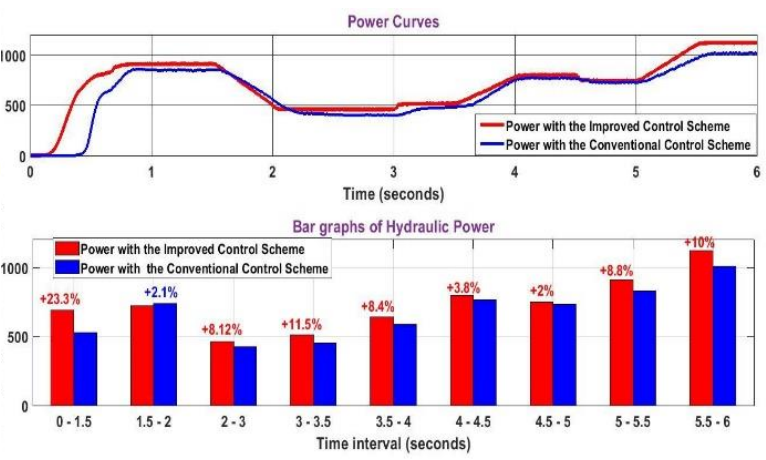

(d)

Figure 8. The motor pump parameters, (a) Rotor speed, (b) Electromagnetic torque (c) Rotor flux, (d) Hydraulic power

\section{CONCLUSION}

An improved control strategy for a batteryless pumping system has been proposed in this contribution. A modified version of the IC method with a variable step size was suggested for MPPT. The CNPC was employed to control the asynchronous motor. A Mamdani type FLC was used to achieve the DClink voltage regulation. Besides, the phase-shift technique was suggested to balance the voltage capacitors of the TLBC. The performances of the modified IC algorithm have been found better than those of the classical IC algorithm. It is found that convergence speed toward the maximum power point was increased two times at the starting with the FLC-MPPT, the power fluctuations were decreased by up to 20 times low irradiances. On the other side, the CNPC showed better performances than the conventional FOC, such as a fast dynamic of the speed, reduced torque ripples, and an ideal decoupling between the torque and the flux. Finally, the DC-link voltage is regulated and balanced, which ensures the proper operation of the TLBC and the threephase inverter. Since the overall results indicated high performances for the unconventional control scheme, then the average hydraulic power was increased from $2 \%$ to $23.3 \%$ in the different irradiances. In the future work, a multilevel inverter will be used to reduce the voltage stress on the power devices as well as to reduce electromagnetic torque ripples. In addition, advanced methods based on artificial intelligence will be implemented to further improve the efficiency of the induction machine.

\section{REFERENCES}

[1] M. Aliyu, G. Hassan, S. A. Said, M. U. Siddiqui, A. T. Alawami, and I. M. Elamin, "A review of solar-powered water pumping systems," Renewable and Sustainable Energy Reviews, vol. 87, pp. 61-76, May 2018, doi: 10.1016/j.rser.2018.02.010.

[2] M. Matam, V. R. Barry, and A. R. Govind, "Optimized Reconfigurable PV array based Photovoltaic waterpumping system," Solar Energy, vol. 170, pp. 1063-1073, Aug. 2018, doi: 10.1016/j.solener.2018.05.046.

[3] S. S. Chandel, M. Nagaraju Naik, and R. Chandel, "Review of solar photovoltaic water pumping system technology for irrigation and community drinking water supplies," Renewable and Sustainable Energy Reviews, vol. 49, pp. 1084-1099, 2015, doi: 10.1016/j.rser.2015.04.083.

[4] T. Radjai, L. Rahmani, S. Mekhilef, and J. P. Gaubert, "Implementation of a modified incremental conductance MPPT algorithm with direct control based on a fuzzy duty cycle change estimator using dSPACE," Solar Energy, vol. 110, pp. 325-337, Dec. 2014, doi: 10.1016/j.solener.2014.09.014.

[5] J. Macaulay and Z. Zhou, "A Fuzzy Logical-Based Variable Step Size P\&O MPPT Algorithm for Photovoltaic System,” Energies, vol. 11, no. 6, p. 1340, May 2018, doi: 10.3390/en11061340. 
[6] Carlos Robles Algarín, John Taborda Giraldo, and Omar Rodríguez Álvarez, "Fuzzy Logic Based MPPT Controller for a PV System,” Energies, vol. 10, no. 12, p. 2036, Dec. 2017, doi: 10.3390/en10122036.

[7] L. Bouselham, M. Hajji, B. Hajji, and H. Bouali, "A New MPPT-based ANN for Photovoltaic System under Partial Shading Conditions,” Energy Procedia, vol. 111, pp. 924-933, Mar. 2017, doi: 10.1016/j.egypro.2017.03.255

[8] B. Talbi, F. Krim, T. Rekioua, S. Mekhilef, A. Laib, and A. Belaout. "A high-performance control scheme for photovoltaic pumping system under sudden irradiance and load changes," Solar Energy, vol. 159, pp. 353-368, Jan. 2018, doi: 10.1016/j.solener.2017.11.009.

[9] H. Chen and W. Lin, "MPPT and Voltage Balancing Control With Sensing Only Inductor Current for PhotovoltaicFed, Three-Level, Boost-Type Converters," in IEEE Transactions on Power Electronics, vol. 29, no. 1, pp. 29-35, Jan. 2014, doi: 10.1109/TPEL.2013.2262056.

[10] C. H. Tran, F. Nollet, N. Essounbouli and A. Hamzaoui, "Modeling and Simulation of Stand Alone Photovoltaic System using Three Level Boost Converter," 2017 International Renewable and Sustainable Energy Conference (IRSEC), Tangier, Morocco, 2017, pp. 1-6, doi: 10.1109/IRSEC.2017.8477246.

[11] G. Yang, H. Yi, C. Chai, B. Huang, Y. Zhang, and Z. Chen, "Predictive Current Control of Boost Three-Level and T-Type Inverters Cascaded in Wind Power Generation Systems," Algorithms, vol. 11, no. 7, p. 92, Jun. 2018, doi: 10.3390/a11070092.

[12] L. A. Vitoi, R. Krishna, D. E. Soman, M. Leijon, and S. K. Kottayil, "Control and implementation of three level boost converter for load voltage regulation," in IECON 2013-39th Annual Conference of the IEEE Industrial Electronics Society, Vienna, Austria, 2013, pp. 561-565.

[13] J. Kwon, B. Kwon and K. Nam, "Three-Phase Photovoltaic System With Three-Level Boosting MPPT Control," in IEEE Transactions on Power Electronics, vol. 23, no. 5, pp. 2319-2327, Sept. 2008, doi: 10.1109/TPEL.2008.2001906.

[14] Z. Guo, M. Zarghami, S. Hou and J. Chen, "Model predictive control for three-level boost converter in photovoltaic systems," 2017 North American Power Symposium (NAPS), Morgantown, WV, 2017, pp. 1-5, doi: 10.1109/NAPS.2017.8107188.

[15] A. Achalhi, D. Ouoba, M. Bezza, N. Belbounaguia and F. Dkhichi, "Application of direct torque control of induction motor in a photovoltaic water pumping system," 2015 3rd International Renewable and Sustainable Energy Conference (IRSEC), Marrakech, Morocco, 2015, pp. 1-5, doi: 10.1109/IRSEC.2015.7454997.

[16] R. Hedjar, R. T. P. Boucher, and D. Dumur, "Cascaded Nonlinear Predictive Control of Induction Motor," European Journal of Control, vol. 10, no. 1, pp. 65-80, 2004, doi: 10.3166/ejc.10.65-80.

[17] A. Merabet, H. Arioui and M. Ouhrouche, "Cascaded Predictive Controller Design for Speed Control and Load Torque Rejection of Induction Motor," 2008 American Control Conference, Seattle, WA, USA, 2008, pp. 11391144, doi: 10.1109/ACC.2008.4586646.

[18] N. Kiran, "Indirect Vector Control of Three Phase Induction Motor using PSIM," Bulletin of Electrical Engineering and Informatics, vol. 3, no. 1, pp. 15-24, 2014, doi: 10.11591/eei.v8i4.1301.

[19] M. Boudjemaa and C. Rachid, "Field Oriented Control of PMSM Supplied by Photovoltaic Source," International Journal of Electrical and Computer Engineering (IJECE), vol. 6, no. 3, Art. no. 3, Jun. 2016, doi: 10.11591/ijece.v6i3.pp1233-1247.

[20] A. Merabet, "Nonlinear Model Predictive Control for Induction Motor Drive," in Frontiers of Model Predictive Control, T. Zheng, Ed. InTech, 2012.

[21] S. Meziane, R. Toufouti, A. Merabet, and H. Benalla, "Cascaded Nonlinear Adaptive Predictive Control based Adaptive Flux Observer of Induction Motor," International Journal of Computer Applications, vol. 56, no. 4, pp. 37-43, 2012.

[22] R. Hedjar, R. Toumi, P. Boucher and D. Dumur, "A finite horizon cascaded nonlinear predictive control of induction motor," 2001 European Control Conference (ECC), Porto, Portugal, 2001, pp. 60-65, doi: 10.23919/ECC.2001.7075882.

[23] Z. Massaq, A. Abounada, G. Chbirik, M. Ramzi and A. Brahmi, "Double Stage Solar PV Array Fed Sensorless Vector Controlled Induction Motor for Irrigational Purpose," 2019 7th International Renewable and Sustainable Energy Conference (IRSEC), Agadir, Morocco, 2019, pp. 1-6, doi: 10.1109/IRSEC48032.2019.9078149.

[24] Z. Massaq, G. Chbirik, A. Abounada, A. Brahmi and M. Ramzi, "Control of Photovoltaic Water Pumping System Employing Non-Linear Predictive Control and Fuzzy Logic Control," International Review on Modelling and Simulations (IREMOS), vol. 13, no. 6, Dec. 2020.

[25] M. Tampubolon et al., "A study and implementation of three-level boost converter with MPPT for PV application," 2017 IEEE 3rd International Future Energy Electronics Conference and ECCE Asia (IFEEC 2017-ECCE Asia), Kaohsiung, 2017, pp. 1143-1148, doi: 10.1109/IFEEC.2017.7992202.

[26] Vongmanee V, Monyakul V and Youngyuan U, "Vector control of induction motor drive system supplied by photovoltaic arrays," IEEE 2002 International Conference on Communications, Circuits and Systems and West Sino Expositions, Chengdu, China, 2002, pp. 1753-1756 vol.2, doi: 10.1109/ICCCAS.2002.1179117.

[27] M. Errouha and A. Derouich, "Study and comparison results of the field-oriented control for photovoltaic water pumping system applied on two cities in Morocco," Bulletin of Electrical Engineering and Informatics (BEEI), vol. 8, no. 4, pp. 1206-1212, 2019, doi: 10.11591/eei.v8i4.1301.

[28] B. Singh, U. Sharma and S. Kumar, "Standalone Photovoltaic Water Pumping System Using Induction Motor Drive With Reduced Sensors," in IEEE Transactions on Industry Applications, vol. 54, no. 4, pp. 3645-3655, July-Aug. 2018, doi: 10.1109/TIA.2018.2825285. 